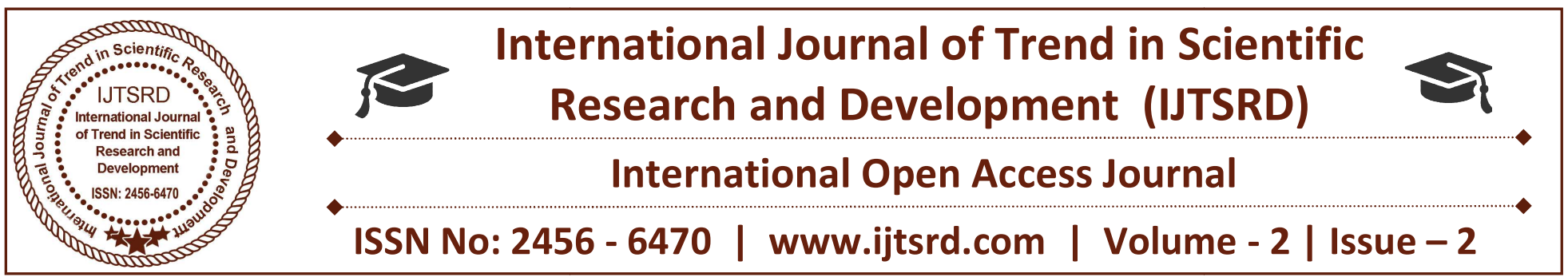

\title{
A Study on Rural Marketing in India: Challenges and Opportunities
}

\author{
Dr. Geeta Yadav \\ Assistant Professor, Indira Gandhi University, \\ Meerpur, Rewari, Haryana, India
}

\section{ABSTRACT}

Rural marketing is a process of developing, pricing, promoting, and distributing rural specific goods and services leading to desired exchange with rural customers to satisfy their needs and wants, and also to achieve organizational objectives In India, except few metropolitan cities, almost all the districts and industrial townships are well connected with rural markets The rural population in India accounts for around 627 million, which is exactly 74.3 percent of the total population. The rural market in India is vast and scattered and offers a plethora of opportunities in comparison to the urban sector. In the recent years, rural markets in India have undergone considerable changes as the urban markets have hit saturation and relative growth has slowed down. Marketers have realized that rural India has tremendous potential and with increasing focus of the policy makers on injecting money to pump the rural economy have all contributed towards an increased interest of businesses towards rural India. Due to green revolution, the rural areas are consuming a large quantity of industrial and manufactured products. In this way rural market offers opportunities in the form of large untapped market, increase in disposable income, increase in literacy level and large scope for penetration. To take the advantage of these opportunities, a special marketing strategy 'Rural Marketing' has emerged. This paper tries to understand the rural market, importance of rural marketing and status of rural market. The main aim of the study to observe the potentiality of Indian rural markets and find out various problems are being faced by rural marketer.

Keywords: Rural Market, FMCG, Rural Consumers

\section{INTRODUCTION}

Marketers are forever seeking fresh challenges and scouting for more and more clientele to be drawn into their sphere of influence. The urban consumer has always been pampered with the most dazzling array of goods and services from every industry. But the urban market is fast shrinking due to saturation caused by the competition, and the growth rate over the past few Years has consistently shown a declining trend. In the hunt for fresh pastures, the vast and Hitherto vastly unexplored terrains of rural India consistently beckon the moolah-seeking marketer. India's growth move is highly driven by the development of the rural people.

"Rural Marketing is defined as a function that manages all activities involved in assessing, stimulating and converting the purchasing power of rural consumers into an effective demand for specific products \& services and moving these products \& services to the people in rural areas to create satisfaction and a better standard of living and thereby achieving organizational goals" (Iyer, 2010).

\section{Features of Indian Rural Markets:}

Large, Diverse and Scattered Market: Rural market in India is large, and scattered into a number of regions. There may be less number of shops available to market products. Major Income of Rural consumers is from Agriculture: Rural Prosperity's tied with 
agriculture prosperity. In the event of a crop failure, the income of the rural masses is directly affected.

Standard of Living and rising disposable income of the rural customers: It is known that majority of the rural population lives below poverty line and has low literacy rate, low per capital income, societal backwardness, low savings, etc. But the new tax structure, good monsoon, government regulation on pricing has created disposable incomes. Today the rural customer spends money to get value and is aware of the happening around him.

Traditional Outlook: Villages develop slowly and have a traditional outlook. Change is a continuous process but most rural people accept change gradually. This is gradually changing due to literacy especially in the youth who have begun to change the outlook in the villages.

Rising literacy levels: It is documented that approximately $45 \%$ of rural Indians are literate. Hence awareness has increases and the farmers are wellinformed about the world around them. They are also educating themselves on the new technology around them and aspiring for a better lifestyle.

Diverse Socioeconomic background: Due to dispersion of geographical areas and uneven land fertility, rural people have disparate socioeconomic background, which ultimately affects the rural market.

Infrastructure Facilities: The infrastructure facilities like cemented roads, warehouses, communication system, and financial facilities are inadequate in rural areas. Hence physical distribution is a challenge to marketers who have found innovative ways to market their products.

\section{RURAL MARKETING IN INDIA}

The concept of rural marketing in Indian economy has always played an influential role in the lives of people. In India, leaving out a few metropolitan cities, all the districts and industrial townships are connected with rural markets. The rural market in India is not a separate entity in itself and it is highly influenced by the sociological and behavioural factors operating in the country. The rural population in India accounts for around 627 million, which is exactly 74.3 percent of the total population. The rural markets in India bring in bigger revenues in the country, as the rural regions comprise of the maximum consumers in this country.
The rural market in Indian economy generates almost more than half of the country's income. Rural marketing in Indian economy can be classified under two broad categories. These are (a) the markets for consumer goods that comprise of both durable and non-durable goods, and (b) the markets for agricultural inputs that include fertilizers, pesticides, seeds, and so on. The concept of rural marketing in India is often been found to form ambiguity in the minds of people who think rural marketing is all about agricultural marketing. However, rural marketing determines the carrying out of business activities bringing in the flow of goods from urban sectors to the rural regions of the country as well as the marketing of various products manufactured by the non-agricultural workers from rural to urban areas.

\section{OBJECTIVES}

1. To understand the rural market.

2. To unleash the potential of rural market.

3. To assess the paradigm/shift from urban to rural market.

\section{OPPORTUNITIES}

The rural market has been growing gradually over the past few years and is now even bigger than the urban market. The saving to income percentage in rural area is $30 \%$ higher than urban area. At present $53 \%$ of all FMCGs and $59 \%$ of consumers durables are being sold in rural area. Major opportunities available in rural market are as follow:

\section{Increase in Literacy Rate}

Literacy rate is increasing in rural areas. According to census 2011 it too There are more graduates in rural than in urban India. This brings social and cultural changes in buying behaviour of the rural customers and more aware about national and international brand. Due to increase in literacy rate they get jobs in nearby towns. They earn urban salaries but continue to live in self owned homes in the villages, they have high purchasing power and prefer to buy branded product

\section{Increasing In Disposable Income and Purchasing Power}

Projects from private companies and the rural employment initiatives by the Government like MNREGA (Mahatma Gandhi National Rural Employment Guarantee Act) schemes have given the 
rural population an opportunity to meet their daily needs. Government decided to expand the agriculture loan at lower rate of interest and distribute million of Kisan Credit Cards, has given a boost to the income level to the rural sector. According to advanced estimates of national income released by centre statistic organization "The Per Capita income at current prices during 2011-12 is estimated to be Rs. 60,972 compared to Rs. 53,332 during 2010-11 showing a rise of $14.3 \%$. Companies have the opportunity to enter in this new market and take the advantage of increased disposable income.

\section{Infrastructure Improving Rapidly}

In 50 years only, $40 \%$ villages have been connected by roads, in next 10 years another $30 \%$ would be connected. Rural telephone density has gone up by $300 \%$ in the last 10 years. Government of India is planning its most ambitious national program in Jan.2013 to facilitate electricity through decentralized renewable energy sources. The government aims to provide LED lights to around 400million homes that do not have an electricity connection by 2017 . Rapid development of rural infrastructure is also major attraction for marketers.

\section{Increase Population and Hence Increase In Demand}

The rural market in India is vast and scattered and offers a plethora of opportunities in comparison to the urban sector. It covers the maximum population and regions and thereby, the maximum number of consumers. More than eighty percent of rural markets in India still do not have access to any sort of organized marketing and distribution.

\section{IT Penetration In Rural India}

Today's rural children and youth will grow up in an environment where they have, ,information access ${ }^{\text {ee }}$ to education opportunities, job opportunities, government schemes, and worldwide news and mandi prices. Rural areas offer a great potential for growth in internet usage with the number of claimed internet users in these spaces to be reached at 45 million by Dec. 2012, according to the recent IMRB survey, conducted jointly with internet and Mobile

Association of India (IMAI). The number of claimed internet users has witnessed a compounded annual growth rate of $73 \%$ since Dec. 2010. As the electronic ethos and IT culture moves into rural India, the possibility of change are becoming visible.

\section{Reduction of Risk During Recession}

It has been observed that companies which cater both urban and rural markets tackle the recession in the better way. The demands for goods in the urban market often follow a cyclic whereas in the rural market it is steady. So companies can safeguard themselves from the harmful effects of recession after entering in the rural market

\section{CHALLENGES}

The peculiarities of rural markets and rural consumers pose challenges to marketers in reaching them effectively. There are a large number of small villages which are not easily accessible because of all weather roads. The main challenges of rural marketing are discussed below:

\section{Transportation Problems}

Transportation is essential for movement of products from urban production centres to remote villages. In rural India transportation facilities are quite poor. Nearly 80 percentages of villages in the country are not connected by well constructed roads. Many parts of India have kwacha roads. Due to poor transportation facilities it is not possible for a marketer to access the rural market.

\section{Warehousing Problems}

A storage function is necessary because there is a time gap between production and consumption of commodities. Agricultural commodities are produced seasonally but they are demanded over the year so there is need to store them. But in rural areas, there is lack of public as well as private warehousing. Marketers face problems of storage of their goods.

\section{Underdeveloped People and Underdeveloped Markets}

Rural society in India is underdeveloped. Modern technology has tried to develop the people and markets in rural areas. But the technology has made very less impact in rural areas.

\section{Inadequate Media Coverage}

Media have lots of problem in rural areas. Television is a good source to communicate the message to rural 
people. But due to non availability of power as well as television sets, majority of rural population cannot get the benefits of various media.

\section{Many Languages}

India is a country of many languages. Language becomes barrier in effective communication in the market efforts. The number of languages vary from state to state, region to region and district to district, etc.

\section{Low Level of Literacy}

The literacy rate is low in rural areas as compared to urban areas. Marketers face communication problem due to the lack of literacy rate. Print medium is not much effective and it is irrelevant since its reach is poor. So, low level of literacy becomes challenge for marketers in rural areas.

\section{Seasonal Demand}

Seasonal demand is main problem of rural market. Agriculture situation plays a significant role in the demand of commodities in the rural market because it is the main source of income. Again agriculture depends on monsoon so buying capacity of rural consumers varies. Despite this, many rural areas are not connected by rail transport. Kuccha roads become unserviceable during monsoon.

\section{CONCLUSION}

The study concluded that rural India offers huge opportunities which companies can tap for their growth and development. However, Companies face many challenges in tackling the rural markets. 833 million people reside in India as compared to 377 millions in urban India so vast untapped opportunities are available in rural India, but marketer unable to tap these opportunities because of lack of infrastructure facilities. Literacy rate is low in rural area so people are unable to identify brand difference. Now trend has gone to change literacy rate in rural area is increasing. Number of middle and higher income household in rural India is expected to grow from 80 million to 111 million. There is rapid development in infrastructure all these opportunities attract companies to target rural market. With some technologies breakthrough in distribution and marketing of products in rural India, companies in rural market can earn more profits, market share, etc. The Rural market is a greater future prospect for the marketers and there are many opportunities available for them in rural markets.

\section{REFERENCES}

1. Anderson James and N Biliou. (2007). Serving the world's poor; innovation at the base of the Economic pyramid. Journal of Business Strategy, 28 (2).

2. Balakrishnan Mandira. (1977). Rural Market: End of a long road for consumer marketers. Decision, July, 177-184

3. Beshouri. (2006). A Grassroots approach to emerging-market consumer. McKinsey Quarterly, 2006, No 4.

4. Dhanabhakyam and shanthi "Article on Indian Retail Industry Growth Challenges", Published and referred in net under www.google.com

5. Gupta S.L., Rural Marketing-Text and cases, Wisdom Publications, Delhi, Ist Edition, 2004.

6. Suja Nair"Retail Management", Himalaya Publishing House, p.p401-429.

7. Swapna Pradhan, "Retailing Management Text\& Cases", Tata Mc Graw Hills Company p.p127141,342-350.

\section{rch and \\ opment}

